\title{
SOSIALISASI KONSEP MANAJEMEN SUMBERDAYA BUDAYA PADA MASYARAKAT DESA HUTAN SEBAGAI UPAYA PELESTARIAN KAWASAN CAGAR BUDAYA PENANGGUNGAN
}

\author{
Reza Hudiyanto*, Ismail Lutfi \\ r.reza.fis@um.ac.id \\ Jurusan Sejarah, Fakultas IImu Sosial, Universitas Negeri Malang \\ Diterima 12 Oktober 2018, dipublikasikan 30 April 2021
}

\begin{abstract}
Cultural remain of the Hindu Buddhist period in Java from the 8th to 15th centuries AD representing cultural diversity in Indonesia. The existence of monuments is often being ignored by the local population for their minimal economic contribution. Practically, it caused a lot of damage to cultural heritage both caused by humans and nature. Therefore, the publishing of the Cultural Heritage Law and the management of cultural resources were carried out in villages located in the area closest to the Penanggungan Cultural Heritage Area. This activity was conducted by compelling most relevant information, drafting in easier grasping text, and selecting obtained feedback from the target group. Published material covers the history of the Penanggungan Temple Area, technical assistance and examples of cultural resource management in Trowulan. From this activity, it can be resumed that the public only have very tiny information about the opportunity offered by managing this the legacy of the Ancient Hindu State Majapahit. Both of these activities need to be followed by assistance and the formation of a main group. This main groups were driving force which has equipped with knowledge of social empowerment, a lot of material with regard to tourism on specific themes, environmental preservation and implementation of the mandate of the Law on Cultural Heritage. By knowing the important of temple, statue and monument in Penanggungan, it has proved increased their sense of preserving cultural heritage.
\end{abstract}

Kata Kunci: Desa Hutan, Sumber Daya Budaya, Pelestarian Kawasan Cagar Budaya

\section{PENDAHULUAN}

Lingkungan merupakan ruang hidup dimana manusia melakukan hubungan dengan alam. Perkembangan peradaban manusia tidak dapat dilepaskan dari kemampuan manusia beradaptasi dengan alam. Karl Wittvogel dalam buku Oriental Despotism menyebut bahwa peradaban manusia berawal dari kemampuan manusia mengembangan sistem organisasi sosial secara lebih luas dan kompleks. Wittvogel menyebut komunitas sungai yang dapat berkembangan menjadi peradaban ini sebagai Hydrolic Society. Hydrolic society ini memiliki kemampuan untuk memperluas dan menambah komunitas manusia. Namun demikian, terdapat keunikan dimana muncul komunitas yang jauh dari Sungai, namun dekat dengan sumber air. Tempat itu adalah kawasan Penanggungan. Kawasan ini telah ditetapkan menjadi Kawasacn Cagar Budya Tingkat Propinsi berdasar Surat Keputusan Gubernur Jawa Timur Nomor 188/18/KPTS/013/2015 tentang penetapan Kawasan Penanggungan sebagai Kawasan Cagar Budaya (KCB) tingkat provinsi (Kemendikbud, 2015).

Kawasan ini telah menjadi perhatian oleh para peneliti sejak era kolonial Belanda. Sebagaimana temuan struktur kuno di tempat lain, kawasan situs Penanggunan ini telah menjadi kajian arkeolog Belanda. Pada umumnya temuan temuan ini diawali dari penemuan benda benda "aneh" ketika dinas Pekerjaan Umum menggali saluran irigasi untuk pengembangan perkebunan tebu. Dalam penggalian itu mereka menemukan struktur dan benda peninggalan Masa Hindu di Jawa Timur. Beberapa bahkan sudah digunakan oleh penduduk sebagai bahan penopang rumah mereka. Temuan awal di daerah dataran rendah ini kemudian diikuti dengan kajian temuan di dataran tinggi setelah Junghuun melakukan ekplorasi dengan menjelajahi berbagai gunung di Jawa. Temiuan arkeholog Belanda itu kemudian menjadi dasar kajian penelitian arkeologi Indonesia maupun asing. 
(Romondt, 1951; Sudjono dkk., 1976; Ibrahim, 1991; Munandar dkk., 1983; SPSP, 1995; Sidomulyo, 2013). Hasil survei yang telah dilakukan menunjukkan tidak kurang 67 situs telah ditemukan kembali pada empat wilayah kecamatan, yaitu Kecamatan Trawas dan Ngoro di wilayah Kabupaten Mojokerto dan Kecamatan Gempol dan Prigen di wilayah Kabupaten Pasuruhan Jawa Timur. Bentuk situs itu berupa struktur dan gua. (Romondt dkk., 1951) menjadi 67 situsPada umumnya hasil perhitungan jumlah situs antara satu peneliti dengan peneliti lain sedikit berbeda. Sebagai contoh hasil temuan dari van Romond, Arismunanda dan Stuterheim menghasilkan angka yang berbeda. Perbedaan ini disebabkan oleh vandalisme, dan kriminalitas terutama pada era pasca 1965. Hal ini salah satu sebabnya adalah pendeknya waktu yang digunakan dalam survei sehingga tidak mampu menjangkau areal yang lebih luas.

Kawasan Cagar Budaya gunung Penanggungan terletak di perbatasan Kabupaten Pasuruan dan Mojokerto. Sebagian besar penduduk kawasan ini bekerja di sektor pertanian lahan kering. Penduduk telah mengenal situs-situs yang berada di kawasan Penanggungan, namun belum menyadari bahwa situs-situs memiliki potensi ekonomi. Oleh karena itu, sebagaian besar upaya perlindungan justru dilakukan oleh masyarakat di luar kawasan tersebut. Ini terlihat saat kebakaran hutan yang melanda kawasan itu pada tahun 2018. Dalam beberapa peristiwa sereingkali terjadi pencurian dan pengrusakan terhadap benda cagar budaya karena jarak antara pemukiman dan situs yang cukup jauh. Hanya ada beberapa budaya yang berada di kaki gunung memang sering terdapat di sekitar pemukiman, seperti kompleks Jedong, situs Balekambang, situs Reco Macan dan situs Suku Domas. Di kawasan itu juga ditemukan inskripsi berupa angka tahun dalam aksara Jawa Kuno pada sejumlah candi dan gua. Khusus angka tahun ini ditampilkan dengan dua model yaitu, deretan angka saja atau candra sangkala baik lamba maupun memet. Sebagai contoh Candi Yudha menampilkan perpaduan angka tahun dan candra sangkalamemet.

Kajian kebudayaan pegunungan merupakan kajian yang perlu banyak dipahami bagi mahasiswa sejarah. Hal ini disebabkan kebudayaan di pegunungan menyimpan potensi pengembangan yang luar biasa. Kondisi ini berbanding terbalik dengan apa yang dijumpai di Situs Penanggunan. Potensi ekonomis di pegunungan terabaikan karena tidak adanya upaya menjadikan situs sebagai sarana belajar. Akses jalan yang disediakan oleh Pemkab Mojokerto masih minim dan tidak termaksimalkan pemanfaatan jasa penduduk sekitar. Beberpa usaha rondah preventif justru berangkat dari inisiatif dari warga seendiri. Ini berdampak terjadi benda-benda cagar budaya dijarah akibat tidak dilibatkannya mansyarakat dan belum adanya kesadaran akan potensi sumberdaya budaya. Oleh karena itu perlu ada kegiatan sosialisasi konsep sumber daya budaya yang ditujukan kepada masyarakat di sekitar desa. Disamping itu, perlu dilakukan sebuah upaya peningkatan kompetensi pada masyarakat agar mampu sedikit mampu mengubah keadaan tersebut.

Pemda setempat melalui dinas pariwisata cenderung memposisikan beberapa situs unggulan semata-mata sebagai sumber penghasil pendapatan asli daerah (PAD). Sementara itu masyarakat yang tinggal di kawasan penelitian sampai sekarang juga belum pernah dilibatkan secara aktif (sebagai subjek) dalam upaya konservasi cagar budaya yang ada di sekitar mereka. Memang ada sejumlah warga masyarakat (komunitas) yang peduli terhadap cagar budaya di kawasan Penanggungan karena berbagai kepentingan tetapi mereka tidak tahu dan menyadari pentingnya konservasi dan bagaimana prosedur pelaksanaannya (Lutfi, 2015). Oleh karena itu, kegiatan ini dilakukan dengan mengoptimalkan peran serta masyarakat melalui berbagai pendekatan community organizing dan community empowerment.

Community organizing: adalah upaya penguatan masyarakat dalam mengorganisasikan dirinya dalam usaha pemberdayaannya. Ini diaplikasikan dalam pembentukan community heritage (Comer, 2004). Pendekatan partisipatoris adalah upaya mengutamakan keterlibatan masyarakat secara langsung dalam kegiatannya. Pendekatan ini antara lain dikenal dengan label PRA (Participatory Rural Appraisal) dan PAR (Participatory Action Research). Semakin intens dan kental keterlibatan atau partisipasi masyarakat dalam konservasi cagar budaya sesungguhnya merupakan inti dari pemberdayaan masyarakat itu sendiri. Adapun pendekatan multidisiplin: pemberdayaan masyarakat mengandung aspek multidimensional, sehingga untuk melakukannya perlu pendekatan multidisipliner agar tujuanya dapat tercapai secara utuh dan efektif. Tentu saja pendekatan ini akan dilakukan ketika 
warga masyarakat yang dilibatkan memang telah memenuhi sejumlah kriteria atau persyaratan. Upaya ini sejalan dengan UU No 112010 tentang Cagar Budaya. UU itu menyebutkan bahwa cagar budaya berupa benda, bangunan, struktur, situs, dan kawasan perlu dikelola oleh pemerintah dan pemerintah daerah dengan meningkatkan peran serta masyarakat untuk melindungi, mengembangkan, dan memanfaatkan cagar budaya.

Berdasar latar belakang tersebut, maka ditetapkan bahwa tujuan kegiatan ini adalah memberikan kesadaran kepada tentang peluang pengembangan jasa transportasi dan penginapan sehingga mau berpartisi dalam pelestarian. Kedua membuka peluang agar situs tidak hanya berfungsi sebagai arel cagar budaya namun juga sebagai sarana rekreasi alam (ecocultural tourism). Ketiga, kegiatan ini diharapkan menjadi rintisan pengembangan tujuan wisata minat khusus di Kawasan Cagar Budaya Penanggunan.

\section{Lingkup Kegiatan:}

Kegiatan ini difokusikan pada penduduk di Desa Kedungudi. Pemilihan ini didasari oleh posisi geografis desa yang berada di zona penyangga Kawasan Cagar Budaya Penanggunan. (Lihat Peta di bawah)

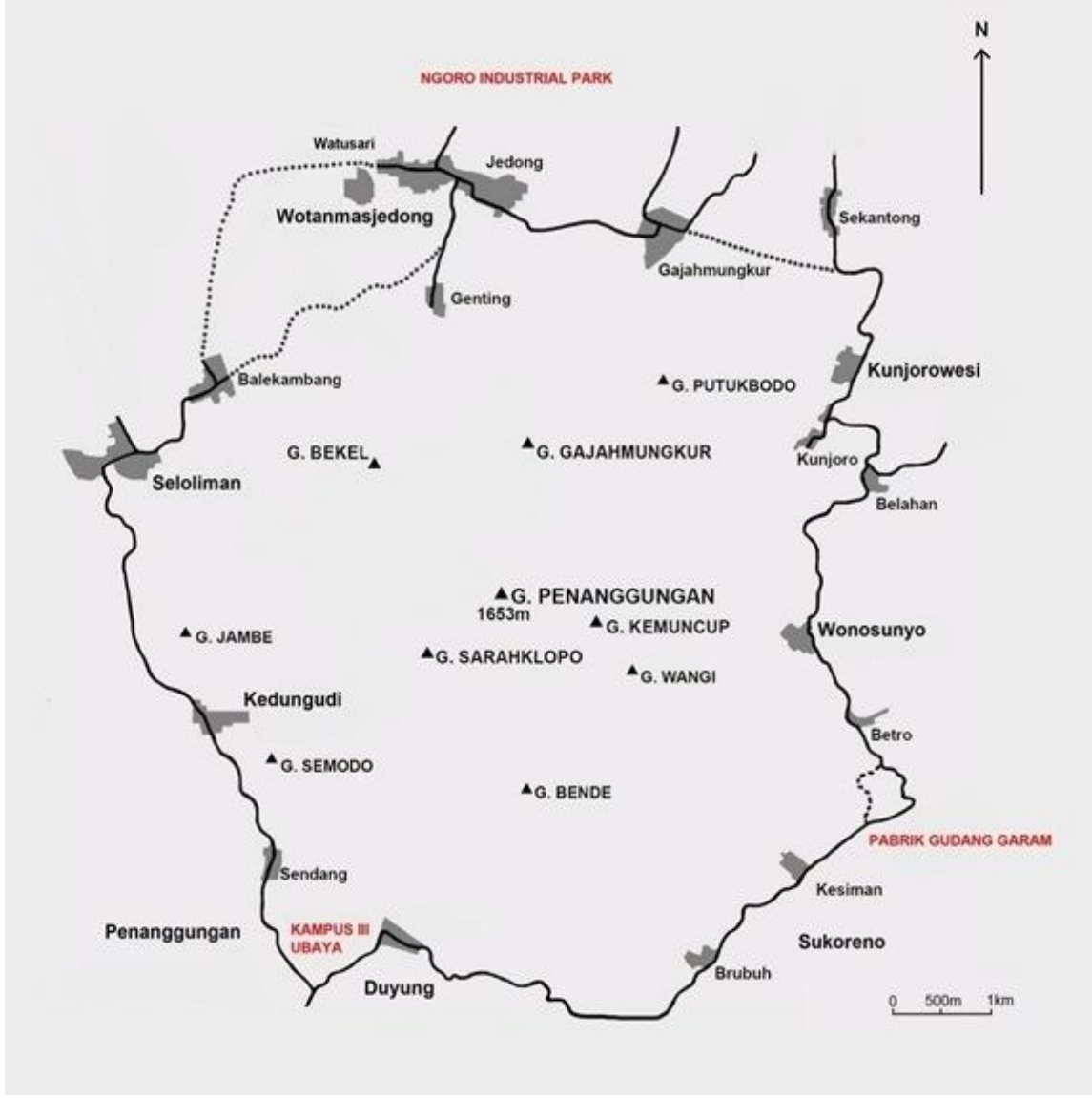

Gambar 1 Kawasan Cagar Budaya Penanggungan

Sumber: Diolah dari Peta Van Romondt 1951, Peninggalan Peninggalan Purbakala di Gunung Penanggungan

Luas Wilayah desa Kedungngudi adalah 700,1 ha. Desa ini dibatasi oleh Desa oleh Seloliman di sebelah utara, Desa Penanggungan di Penanggungan di Sebelah Selatan, wilayah PERHUTANI (Perusahaan Hutan Indonesia) di Sisi barat. Suhu rata-rata Kedungngudi adalah 28 derajat Celcius Desa ini berada di ketinggian 500 meter di atas permukaan laut. Ada tanah (tanah bengkok) seluas 11,41 dan sebagian besar tanah subur adalah tegalan (tanah kering). Jumlah lahan sawah basah tidak seluar lahan kering. Menurut laporan statistik desa, jumlah total populasi adalah 581 yang terdiri atas 445 pria dan 436 wanita. Jika dilihat dari standar tingkat pendidikan, kualitas sumber daya manusia di desa ini cukup rendah karena sebagian besar penduduk di Desa ini hanya lulusan 
sekolah dasar. Data ini akan ditampilkan yaitu sejumlah 247 orang . Sementara jumlah lulusan SMP adaah 48 lulusan, SMA sebesar 29 orang dan hanya 6 lulusan universitas. Satu-satunya fasilitas pendidikan yang ada di tempat ini adalah sekolah dasar. Hanya ada dua sekolah dasar dengan 9 guru dan 94 murid. Satu-satunya fasilitas kesehatan adalah klinik.

Dua profesi yang ada di desa ini adalah pekerja mandiri (sebagai petani, pedagang, tukang kayu) dan tenaga kerja industri skala kecil. Luas lahan untuk tanaman pokok mencapai 21,30 hektar. Sementara itu sebagai tanaman pokok kedua, jagung dan singkong hanya mencakup 5 hektar. Produk budidaya lokal lainnya adalah kopi dan kemiri. Sebagian besar lahan lain di desa Kedungudi terdiri dari Hutan, yaitu 520 ha. Orang-orang di Kedungudi juga memelihara ternak dan unggas antara lain adalah ayam, bebek, kambing dan sapi. Tapi sebagian besar jenis binatang itu menjadi sarana hidup bagi warga desa adalah ayam. Enam vendor kecil dan tujuh kantin tradisional menandai kegiatan di luar pertanian di tempat ini. Tidak ada motel, hotel, dan pondok yang bisa mendiversifikasi profesi penduduk desa di Kedungngudi. Pertanian Padi telah menjadi pekerjaan utama bagi mayoritas orang-orang di desa Kedungngudi. Faktor ekonomi adalah salah satu dari banyak alasan di balik perilaku mengabaikan warisan budaya yang sangat dekat dengan mereka. Sebagian besar panen panen dijual ke pasar dan sisanya dikonsumsi untuk kebutuhan mereka sendiri. Selain itu, banyak warga sekitar KCB Penanggungan menjadi pencari dan peternak madu dan burung. Mereka sadar bahwa ada banyak bangunan kuno peningggalan jaman Hindu Buddha di sekitar gunung. Kesibukan mereka dalam memenuhi kebutuhan dasar mereka - seperti makanan dan pendidikan, telah membuat mereka kurang memberikan perhatian pada warisan budaya. Disamping itu, jarak antar Desa Kedungnudi dengan situs agak jauh sehingga intensitas penjagaan menjadi lemah.

Upaya konservasi ini perlu dilakukan karena sering terjadinya pencurian, pengrusakan dan tindakan vandalisme lain. Data dari UNESCO menyebutkan pencurian barang antik itu terkait dengan perdagangan internasional lintas negara. Nilai transaksi barang itu cukup menarik, sebagai contoh lukian Van Gogh mencapai nilai $\$ 53,9$ Juta dan Picasso mencapai $\$ 47,85$ juta. Penjarahan dan pencurian benda antik bukan merupakan fenomena baru. Bagi UNESCO, perdagangan internasional barang barang seni, antik ini merupakan pembajakan warisan budaya dan menghilangkan petunjuk bagi ilmuwan yang mengkaji kebudayaan masa lalu.

Dari sisi alam, ancaman keutuhan struktur, dan dan bangunan adalah bencana pada permukaan tanah seperti tanah longsor dan gempa bumi. Pada 30 September 1993, terjadi gempa bumi 6,3 Skala Richter di Latur, sebuah kawasan Desa Kuna 500 Km sebelah Timur Bombay. Bencana ini mengakibatkan 9000 orang meninggal dunia, 16.000 orang cedera dan 90.000 rumah rusak. Akan tetapi yang menjadi perhatian adalah wilayah Latur adalah pemukiman kuno, yang mana disekitarnya masih terdapat benda benda seperti dinding, tembok rumah dengan ketebalan batu 600 $\mathrm{mm}$ dengan pelekat lumpur. Wilayah itu juga memilik sejarah panjang sejak era Pra-Aksara. Ketika terjadi gempa semua bangunan yang merupakan tipologi vernacular housing itu roboh. Selain menghancurkan situs budaya, upaya rekonstruksi pasca gempa juga menimbulkan konflik karean penduduk menginginkan bentuk permukiman tidak berubah, namun pihak yang akan memugar berdalih bentuk bangunan itu sangat riskan terhadap bahaya gempa bumi. Akhirnya Pihak World Bank kemudian mendanai proyek rekonstuksi dengan tetap memperhatikan bentuk asli dan tingkat kemanan terhadap gempa (adaptasi).

Ancaman lain terhadap situs adalah konflik politik. Penghancuran sebuah situs budaya bahkan menjadi bagian dari perang antar kelompok etnis dan agama. Situs dianggap sebagai lambang eksistensi etnis lawan yang harus dihancurkan. Ini terjadi pada Masjid Babri yang berasal dari abad ke-16 yang dihancurkan oleh ekstrimis Hindu saat konfli Islam Hindu pecah di Ayodya, India tahun 1992. Aksi tersebut dibalas dengan perobohan Kuil Jaina di Lahore, Pakistan. Bangunan heritage Kuil Jaina ini menjadi sasaran diduga karana menjadi identitas kolektif agama dari masyarakat etnis tertentu. Seringkali, bukan hanya bangunan fisik, arsip yang memberikan memori eksistensi etnis tertentu juga menjadi korban sebagaimana yang terjadi di Kukasus pada tahu 1993. Pada waktu Perang Abkhazia, sekolompok militan Georgia me,empar granat ke geudang arsi Abkhazia, karena arsip tiu diangggap sebagai penguat idneitas etnis Abkhazia, namun jug abukti bahwa Yahudi, Yunana, Armenia dan Rusia pernah membentuk masyarakat multikultural di Abkhazia. Upaya 
pencarian kembali akar budaya yang melekat pada bangunan heritage ini semakin kuat seiring dengan revival of cultural tradition, pada era pasca perang.

\section{METODE}

Metode dalam kegiatan ini adalah metode sosial. Tahap kegiatan pertama adalah perumusan instrumen penelitian berdasarkan penelitian terdahulu. Tahap kegiatan kedua adalah melakukan observasi dengan panduan instrumen penelitian. Sasaran observasi adalah berbagai situs yang tersebar, di kawasan Pasuruan dan Mojokerto, khususnya situs-situs yang berada di kawasan pegunungan dan hasil penggalian informasi dari tokoh masyarakat setempat. Informasi yang diperoleh dari observasi ini dijadikan bahan analisis untuk penyusunan materi sosialisasi. Salah satu data yang diperoleh adalah masih sedikitnya jumlah situs tereksplorasi secara umum di publik. Hanya beberapa objek situs besar yang sudah sering dijadikan sebagai objek kegiatan baik oleh Balai Pelestarian Cagar Budaya maupun laboratorium lapangan Universitas Negeri Malang. Tahap kegiatan ketiga adalah mengurus perijinan. Kegiatan sosialisasi ini dirancang dalam bentuk saresehan dan dialog dengan penduduk di sebuah desa yang memiliki radius paling dekat dengan situs yaitu Kedungudi dan Seloliman. Sebagai pembicara adalah seorang akademisi yang memiliki kompetensi terhadap situs cagar budaya gunung Penanggungan yaitu Drs, Ismail Lutfi, M.A. Sementara itu, pembicara kedua mewakili dari pihak desa yaitu Kepala Desa Kedungudi. Tahap keempat adalah pelaksanaan kegiatan adalah penulisan hasil sosialisasi dan perumusan saransaran.

\section{HASIL DAN PEMBAHASAN}

Kegiatan sosialisasi ini merupakan kegiatan inti dalam rangkaian kegiatan di Desa Kedungngudi. Bahan untuk sosialisasi tidak hanya hasil observasi namun juga hasil kajian akademis dari nara sumber. Pada awalnya, kegiatan ini ingin memberika fokus pada situs Penanggungan, akan tetapi karena objek ini telah banyak diteliti oleh para ilmuwan, maka foklus dialihkan pada masyarakat penyangga cagar budaya. Kedudukan mereka sering dikesampingkan dalam aktivitas penelitian. Oleh karena itu, langkah pertama adalah melakukan interview dengan pihak pamong desa Kedungngudi, terutama berkaitan dengan tanggal pelaksanaan yang harus menyesuaikan dengan pertemuan warga. Berdasarkan saran dari Kepala Urusan Pemerintahan, kegiatan dilakukan saat pertemuan arisan warga RT.

Kegiatan sosialisasi ini berlangsung di rumah warga desa Kedungudi, jam 19.30. Dalam kegiatan ini, Drs, Ismail Lutfi selaku akademisi yang meneliti kawasan Cagar Budya Penanggunan menyampaikan materi Sumberdaya Budaya di Kawasan Cagar Budaya Gunung Penanggungan.

Di dalam penyampaian itu ditayangkan beberapa struktur bangunan, baik yang masih utuh, sebagian hancur atau yang hampir mengalami kerusakan secara keseluruhan. Disamping bangunan, berdasar pemotretan dengan pesarat drone, terlihat adanya jalur tua yang dipergunakan olah masyarakat sebagai jalan setapak, pada kurang lebih abad 9 hingga 14 Masehi. Kawasan itu menghubungan satu objek dengan objek lain, dari ketinggian 1200 hingga 900 meter dari permukaan air laut. Pada tayangan slide berikutnya ditunjukkan adanya struktur yang terancam roboh karena tanah di bawahnya yang tidak lagi menopang. Di slide berikutnya ditunjukkan sebuah gambar yang menunjukkan benda yang seharusnya ada di tempatnya, ternyata sudah tidak ada.

Pada slide video, narasumber menunjukkan contoh kelompok sadar wisata yang telah terbentuk di kawasan cagar budaya Trowulan. Di dalam film singkat tersebut, terlihat masyarakat sudah mampu menangkap peluang yang didapat dari adanya situs cagar budaya Trowulan dengan pengembangan kerajinan cindera mata bermotif lokal. Usaha lain yang bermunculan adalah kuliner dan perdagangan konveksi. Atas dasar pengalaman di wilayah KCB Trowulan tersebut, narasumber memantik peserta untuk membayangkan jika kawasan Penanggungan ini bisa terpublikasi, pasti akan membuka peluang usaha baru. Selama ini potensi alam yang baru tergali di desa Kedungngudi adalah Kemiri dan buah alpukat yang dijual di sepanjang jalan. Jalanan itu memang lebar dan halus, namun masih jarang dilewati karena tidak adanya "magnet" yang bisa menarik orang untuk berkunjung ke Desa desa di kawasan penyangga Cagar Budaya tersebut. Dalam bagian terakhir 
narasumber mengajak penduduk untuk memperhatikan keamanan dari kawasan cagar budaya tersebut.

Konservasi sumberdaya arkeologi (SDA) di kawasan tersebut sudah seharusnya dilakukan secara tepat, efektif dan efisien. Hal ini mendesak karena kondisi lingkungan berada SDA itu rawan terhadap bencana alam dan gangguan orang-orang yang sengaja bertindak jahat maupun ulah para pendaki. Sekalipun tampak upaya dari pihak Balai Pelestarian Cagar Budaya (BPCB) Jawa Timur untuk menata sejumlah situs serta lingkungan di sekitarnya, hal itu masih jauh dari memadai. Hampir semua situs yang ada berada dalam kerawanan terutama ancaman terkena longsor ataupun mengalami longsor. Salah satu faktor penyebab longsor adalah hilangnya vegetasi karena kebakaran hutan seperti terjadi pada bulan Nopember tahun 2013 telah mengakibatkan seluruh puncak gunung Bekel kehilangan vegetasi. Hal ini akan sangat membahayakan keberadaan struktur bangunan situs, apalagi bila turun hujan. Tanah longsor akan menggerus pondasi bangunan kuno yang hanya diperkuat susunan batu batu andesit.

Selama ini tindakan preventif pelestarian situs yang meliputi pemeliharaan, perawatan, pengawasan dan pengamanan dalam rangka konservasi terhadap SDA di kawasan Penanggungan utamanya dilakukan oleh para Juru Pelihara (Jupel) yang bekerja atas nama Balai Pelestarian Cagar Budaya (BPCB) Jawa Timur di Trowulan. Keamanan memang telah diperketat, sebagian dari peninggalan di lereng barat dan utara gunung kini diawasi dan dijaga dengan baik oleh sekelompok Jupel setempat yang berkedudukan di desa Kedungudi, Seloliman, Jedong, Genting serta Kunjorowesi. Berapapun jumlah juru pelihara yang dipekerjakan di kawasan ini tentu saja tidak akan mampu melakukan pemeliharaan dan pengamanan semua situs yang ada mengingat medan yang mereka hadapi berupa gunung lengkap dengan hutan, lembah, dan jurang. Hal ini pula yang menjadi alasan lain kajian ini dilakukan.

Berdasarkan kegiatan yang yang dilakukan di desa ini pada tanggal 6 Juni 2015 terdapat beberapa informasi dari warga desa. Warga desa memerlukan pendampingan dalam penerapan konsep pengelolaan sumber daya budaya. Masyarakat tidak berkeberatan untuk mendukung langkah-langkah pengamanan yang lebih ketat, terutama pada lokasi-lokasi peninggalan yang rawan bencana dan rawan pencurian. Penduduk selama ini telah melakukan penataan terhadap bangunan dan lingkungan di sekitarnya, termasuk perbaikan saluran air serta penghijauan.

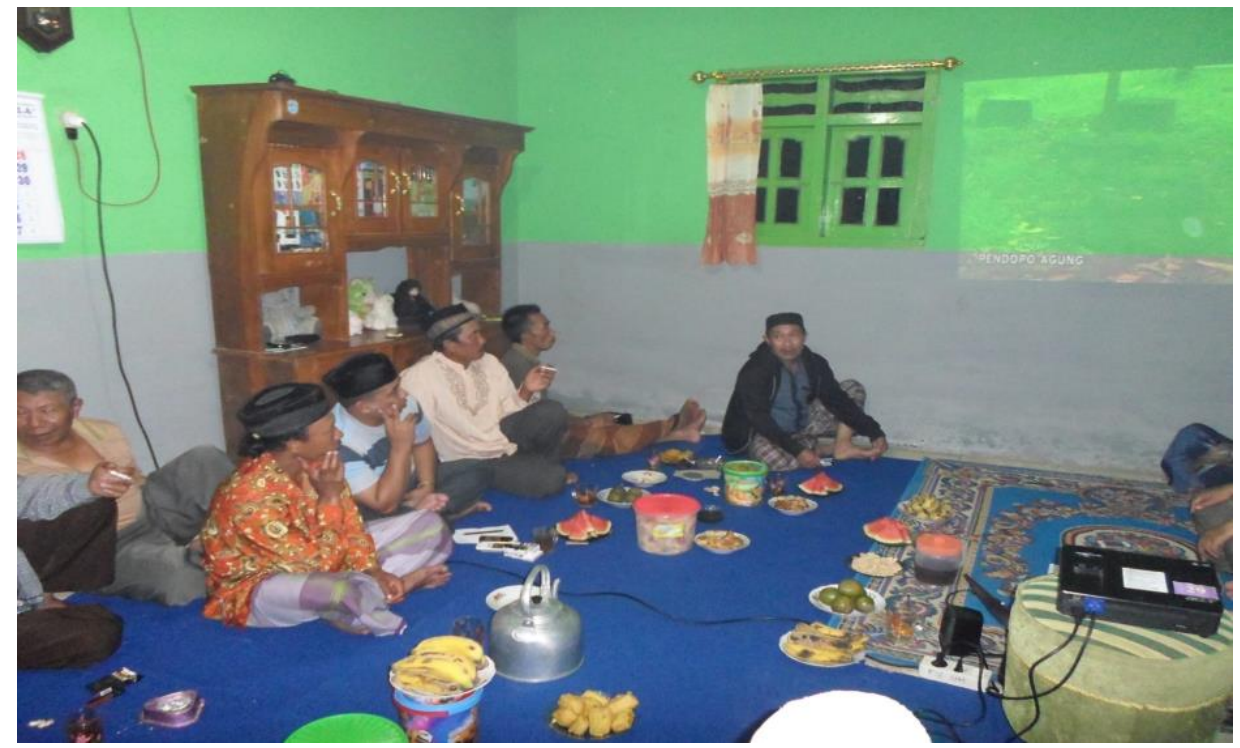

Gambar 2 Foto Kegiatan Sosialisasi awal di Pertemuan warga Desa Kedungngudi: Juni 2015 Sumber: Hudiyanto, 2015

Dalam hal terakhir ini disarankan agar penanaman pohon-pohon besar tidak terlalu dekat dengan bangunan, karena akarnya nanti dapat merusak fondasinya. Penataan ini dilakukan pada kawasan baik di sekitar situs maupun jalan untuk pendakian, dan membuat shelter untuk tempat peristirahatan para pendaki atau wisatawan. Perangkat desa dalam hal ini Lurah menghendaki, 
pendampingan untuk rintisan kerjasama dengan Pemerintah Kabupaten Mojokerto. Perangkat desa juga meminta pembekalan dalam merintis kerjasama dengan perusahaan agar memperoleh dukungan finansial melalui program Corporate Social Responsibility, Dukungan ini diperlukan untuk pengembangan spot-spot yang akan dikembangkan menjadi objek kunjungan. (Pertemuan tanggal 6 Juni 2015) Berdasar pertemuan ini, hambatan paling besar dalam upaya memanfaatkan sumber daya budaya bagi kesejahteraan masyarakat adalah permodalan. Pembentukan Kelompok Sadar Wisata dapat dijadikan awal gerakan Pelestarian sekaligus Pemanfaatan kawasan cagar budaya bagi kemajuan desa.

\section{KESIMPULAN}

Bangunan dan struktur bersejarah di dalam Kawasan Cagar Budaya Penanggungan adalah sumberdaya arkeologi yang berpotensi sebagai komponen pembentuk sejarah perkembangan kawasan ini. Sumberdaya tersebut memiliki nilai manfaat dan mengandung nilai penting sejarah, ilmu pengetahuan, agama maupun keudayaan. Dalam rangka menjaga kelestarian Sumber Daya Alam di Kawasan Penanggungan, disamping menggunakan mekanisme konservasi yang sudah ada, pemberdayaan masyarakat menjadi penting dan memberikan sumbangan yang berarti.

Bentuk pemberdayaan masyarakat yang dimaksud adalah pelibatan secara langsung melalui kegiatan di lapangan, pendidikan dan pendampingan secara berkesinambungan serta mengikutsertakan dalam pengambilan keputusan. Di samping itu warga masyarakat yang mempunyai potensi dan kemampuan dalam dunia pariwisata akan dipromosikan sebagai ujung tombak pelestarian pada bidang pemanfaatan SDA khususnya sektor wisata. Setelah dilakukan sosialisasi, masyarakat mengerti adanya UU Cagar Budaya No. 11 Tahun 2010. Masyarakat mengerti adanya SK Gubernur Jatim No. 188/18/KPTS/013/2015, Tentang: Penetapan Satuan Ruang Geografis Kawasan Penanggungan Sebagai Kawasan Cagar Budaya Peringkat Propinsi. Dengan bekal pengetahuan ini, kegiatan ini dapat ditindaklanjuti dengan pembentukan kelompok inti yang menggiatkan kegiatan pelestarian. Kerjasama antara perguruan tinggi, pihak desa selaku tokoh formal masyarakat desa dengan Perhutani menjadi sangat penting. Pengelolaan Kawasan Situs sering berbenturan dengan pihak Kawasan Pemangku Hutan (KPH) Pasuruan yang menjadi pemilik kawasan hutan di seluruh kaki Gunung Penanggunan.

Masyarakat paham dan sadar bahwa dekat dengan lingkungan tinggal mereka merupakan museum alam (ecomuseum). Masyarakat sadar dan makin paham peran serta dan keterlibatannya dalam pelestarian kawasan cagar budaya adalah tuntutan UU. masyarakat memiliki antusiasme untuk berperan aktif dalam pelestarian cagar budaya. Masyarakat mengerti benar bahwa di kawasan mereka tinggal terdapat cagar budaya yang melimpah. Dalam pelestarian cagar budaya, masyarakat membutuhkan pendampingan. Masyarakat dapat melihat dan menangkap peluang usaha terkait pelestarian kawasan cagar budaya khususnya aspek pemanfaatan dalam rangka pariwisata. Masyarakat mengharap dukungan dari berbagai pemangku kepentingan dalam pelestarian cagar budaya.

\section{DAFTAR PUSTAKA}

Atmodjo, J.S. 1983. "Punden berundak di Gunung Penanggungan". Skripsi. Fakultas Sastra Universitas Indonesia.Jakarta

BPS Kabupaten Mojokerto, 2014. Kecamatan Trawas dalam Angka 2014. Mojokerto: BPS Kabupaten Mojokerto.

Brandes, J.L.A., 1913. Oud-Javaansche Oorkonden. Verhandelingan Batavia Genotschapp deel LX. Batavia: Albrecht \& Co.

Detik News, Selasa, 02 Okt 2018

Ibrahim, M. dkk. 1991/1992. Laporan Kegiatan Penentuan Batas Wilayah Cagar Budaya dalam rangka Penyelamatan Situs Gunung Penanggungan dan Sekitarnya. Jakarta: BAKOSURTANAL, DITLINBINJARAH, LIPI.

Jeniffer N Lehman,"The Continued Struggle with Stolen Cultural Property". The Haque Convention, The UNESCO Convention and The Unidroit Draft Convention. Aris J Intl \& Comp, 1997 
Jigyasu, R. 2001. From Natural to Cultural Disaster: Consqequences of the Post-earthquake Rehabilitation Process on the Cultural Heritage in Marawath Region India". Bulletin of Zealand Society for Earthquake Engineering Vol 34 No 3 September 2001, pg 237-9

Kemendikbud, 2015. Penetapan Kawasan Cagar Budaya Penanggungan oleh Gubernur Jawa Timur http: //kebudayaan.kemdikbud.go.id/ bpcbtrowulan/ 2014/12/16/ penetapan-kawasan-cagarbudaya-oleh-gubernur-jawa-timur

Koentjaraningrat, 1989, Metode Metode Penelitian Masyarakat. Jakarta: Gramedia

Lutfi, I. 2015. "Partisipasi Komunitas Warisan Budaya dalam Konservasi Kawasan Cagar Budaya Penanggungan". Tesis. Jogjakarta: Fakultas Ilmu Budaya Universitas Gadjah Mada.

Mark Janse (ed), Productivity and Creativity, Studie in General and Descriptive Linguistic in HonorE M Uhlenbeck. New York: Mouton de Gruyter, 1998

Monografi Desa Kedungngudi 2007, Koleksi Pemerintahan Desa Kedungngudi, Kecamatan Trawas Kabupaten Mojokerto.

Munandar, A.A. 1990a. Kegiatan keagamaan di Pawitra, gunung suci di Jawa Timur abad 14-15 (tesis). Jakarta: Fakultas Sastra Universitas Indonesia.

Munandar, A.A. 1990b. "Arca dan Relief pada Kepurbakalaan Gunung Penganggungan: Pembicaraan Ringkas Aspek Keagamaan" dalam Monumen. Jakarta: Fakultas Sastra Universitas Indonesia.

Munandar, A.A. 1993. Gunung Penanggungan sebagai Tempat Kegiatan Kaum Rsi. Laporan Penelitian. Jakarta: FSUI

Price, Nicholas Stanley (eds), Cultural Heritage in Postwar Recovery. Rome, International Centre for Study of Preservation and Restoration of Cultural Property, 2007

Romondt, V.R. van, Oey-Blom, J., Ichwani. 1951. Peninggalan-peninggalan purbakala di Gunung Penanggungan. Jakarta: Dinas Purbakala Republik Indonesia.

Sahid, N. 1990. Kerusakan dan Pelapukan Bangunan Punden Berundak di Gunung Penanggungan. Skripsi.Drs. Fakultas Sastra Universitas Indonesia.Jakarta

Salamun Budiono. Wawancara tanggal 16 Juni 2017.

Sidomulyo, H. 2013. Mengenal Gunung Penanggungan. Surabaya: Ubaya Press

Suaka Peninggalan Sejarah dan Purbakala, 1995. Laporan Pendataan dan Registrasi Kepurbakalaan di Mojokerto. (T.T).

Sudjono, T. dkk., 1976. Laporan Hasil Survei Kepurbakalaan di Gunung Penanggungan. BPA 